\title{
Biochemical Variations of Serum Magnesium with Lipid Analytes in Different Clinical Groups of Type 1 and Type 2 Diabetes Mellitus: A Hospital-based Cross-sectional Study
}

\author{
Prashant Kumar ${ }^{1}$, Shashi Ranjan ${ }^{2}$, Himani Rathi ${ }^{3}$, Raman Kumar ${ }^{4}$, Shilpa Puluturu ${ }^{5}$, Bela Goyal ${ }^{6}$, Manisha Naithani ${ }^{7}$,
} Swati Rajput ${ }^{8}$, Satyavati Rana ${ }^{9}$, Senkadhirdasan Dakshinamurthy ${ }^{10}$, Ravi Kant ${ }^{11}$, Anissa A Mirza ${ }^{12}$

\begin{abstract}
Objective: Hypomagnesemia associated with dyslipidemia in type 2 diabetes mellitus (T2DM) has been well documented globally by various researchers, as there found a paucity in related data for type 1 diabetes mellitus (T1DM), present observational hospital-based cross-sectional study was planned to estimate, correlate serum magnesium with lipid analytes in different clinical groups of both T1DM and T2DM, and validate its diagnostic significance.

Materials and methods: The study comprised 250 subjects with random inclusion of 200 of both T1DM, T2DM, and 50 normoglycemic healthy controls. Based on medical history and clinical records of 52 T1DM and 148 T2DM clinical cases, they were subgrouped into group I-newly diagnosed, group II-stabilized controlled, and group III-with long course, uncontrolled with associated complications. Biochemical analyses of plasma glucose, serum total magnesium, total cholesterol, and triacylglycerol were analyzed, compared, and correlated statistically with each group and healthy controls.

Results: Comparison and correlations of studied analytes in T1DM and T2DM groups of subgroups with healthy controls, clearly depicted biochemical variations of hypomagnesemia in overt hyperglycemic-hyperlipidemic clinical cases. Hypomagnesemia was inversely correlated with hypertriacylglycerolemia and hypercholesterolemia in hyperglycemic of both T1DM and T2DM with varied statistical significances in different clinical groups with $(p<0.001)$ in group III, $(p<0.01)$ in group I, and $(p>0.05)$ non-significant in group II. However, no statistical significance $(p>0.05)$ for analytes was noted between type 1 and type 2 of all subgroups.

Conclusion: As biochemical variations of hypomagnesemia in overt hyperglycemic-hyperlipidemic type 1 and type 2 clinical cases of diabetes mellitus was depicted and correlated, it is recommended for clinicians to prescribe serum magnesium as a routine investigation of diabetes diagnostic profile for early screening, periodic monitoring, and better management with its supplementation to prevent long-standing critical diabetes complications.
\end{abstract}

Keywords: Hypercholesterolemia, Hypertriacylglycerolemia, Hypomagnesemia, Type 1 and type 2 diabetes mellitus.

Indian Journal of Medical Biochemistry (2020): 10.5005/jp-journals-10054-0162

\section{INTRODUCTION}

Diabetes mellitus (DM) a chronic, endocrine-metabolic-clinical syndrome characterized by overt hyperglycemia, due to an insufficiency or inefficiency of insulin with increased morbidity and mortality is currently a serious pandemic. The prevalence of type 2 diabetes mellitus (T2DM) is higher than type 1 diabetes mellitus (T1DM). ${ }^{1}$ World Health Organization states the prevalence of T2DM has raised dramatically up to 422 million people worldwide in conjunction with an increased westernization of the population's lifestyle in all income levels. ${ }^{2}$ Diabetes mellitus is considered a giant killer disease of the 21st century with the largest number of subjects predicted to be suffered in India, China, and the USA by 2030, where India, is already known as the "Diabetes Capital" of the world. ${ }^{3,4}$

In DM, the overall metabolism of biomolecules gets deranged along with disturbances in minerals and electrolytes. ${ }^{5}$ Magnesium is a fourth-most-abundant, nutritionally essential macromineral, ingested through common foods of plant and animal origin. It is a free divalent cation of cells deeply and intrinsically woven into cellular metabolism involved with various structural and metabolic functions of the human body. It mainly serves as an inorganic cofactor for most of the enzyme systems that regulate diverse biochemical reactions of carbohydrate, lipid, and protein metabolism for energy production through oxidative
1-9,12 Department of Biochemistry, All India Institute of Medical Sciences, Rishikesh, Uttarakhand, India

${ }^{10}$ Department of Community Family Medicine, All India Institute of Medical Sciences, Rishikesh, Uttarakhand, India

${ }^{11}$ Department of Medicine, All India Institute of Medical Sciences, Rishikesh, Uttarakhand, India

Corresponding Author: Anissa A Mirza, Department of Biochemistry, All India Institute of Medical Sciences, Rishikesh, Uttarakhand, India, Phone: +91 7060200259, e-mail: anissa.bchem@aiimsrishikesh.edu.in

How to cite this article: Kumar $\mathrm{P}$, Ranjan $\mathrm{S}$, Rathi $\mathrm{H}$, et al. Biochemical Variations of Serum Magnesium with Lipid Analytes in Different Clinical Groups of Type 1 and Type 2 Diabetes Mellitus: A Hospital-based Crosssectional Study. Indian J Med Biochem 2020;24(3):119-124.

Source of support: Nil

Conflict of interest: None

phosphorylation. ${ }^{6}$ It is indirectly associated with the structural development of bones, DNA, RNA biosynthesis, the antioxidant activity of glutathione, and homeostasis of plasma glucose and blood pressure. Magnesium predominates in the active transport of potassium and calcium ions as a signaling molecule for conduction of nerve impulse, contraction of muscle, and generate normal heart

(0) The Author(s). 2020 Open Access This article is distributed under the terms of the Creative Commons Attribution 4.0 International License (https:// creativecommons.org/licenses/by-nc/4.0/), which permits unrestricted use, distribution, and non-commercial reproduction in any medium, provided you give appropriate credit to the original author(s) and the source, provide a link to the Creative Commons license, and indicate if changes were made. The Creative Commons Public Domain Dedication waiver (http://creativecommons.org/publicdomain/zero/1.0/) applies to the data made available in this article, unless otherwise stated. 
rhythm. Severe hypomagnesemia frequently causes muscle spasms, associated with anxiety disorders, migraines, osteoporosis, high blood pressure, cardiovascular disease, and infarction. There is a complex interaction between insulin resistance and magnesium. Magnesium is well documented to have an important role in the pathogenesis of diabetes and its complications with derangements in the heart, blood vessels, eyes, kidneys, and nerves. ${ }^{7}$ Regulated magnesium levels have received considerable attention for its potency to improve insulin sensitivity in DM with cardiovascular complications. ${ }^{8}$ Magnesium deficit showed clinical consequences of chronic post-receptor insulin resistance that reduces glucose utilization in cells, aggravating decreased insulin sensitivity in T2DM. ${ }^{9}$ Diabetes mellitus can induce hypomagnesemia, which is a risk factor for its various complications. ${ }^{10-13}$ A negative impact of hypomagnesemia on glucose homeostasis and insulin sensitivity in patients with T2DM was depicted with the evolution of DM complications, such as, arterial atherosclerosis, retinopathy, and nephropathy. ${ }^{14,15}$ Hypomagnesemia in patients with type 2 diabetes was associated with several chronic diseases, such as Alzheimer's disease, hypertension, cardiovascular disease, stroke, migraine headaches, and attention deficit hyperactivity disorder. ${ }^{16}$ Myocardial magnesium depletion was interlinked with an influx of $\mathrm{Na}^{+}$and $\mathrm{Ca}^{2+}$ into mitochondria that may lead to myocardial cell death and increase the risk of secondary complications. ${ }^{17}$

Dyslipidemia a frequent feature of insulin resistance syndrome is another risk factor for pathogenesis in T2DM. Hypomagnesemia has a role in the perturbation of lipid metabolism in DM. ${ }^{18}$ It was demonstrated that subjects with hypertension have a marked increase in the prevalence of hypercholesterolemia, DM, hypomagnesemia, and hypertriglyceridemia. ${ }^{19} \mathrm{~A}$ literature search of previous epidemiological studies showed serum magnesium was associated and correlated with various biochemical analytes mostly in T2DM with a paucity of evidence in T1DM. In consideration of all reviewed facts, a present observational, hospital-based crosssectional study was planned at an Indian government hospital to identify biochemical variations of fasting plasma glucose, serum magnesium, and major lipid analytes serum total cholesterol and triacylglycerol in different clinical groups of both T1DM and T2DM to be compared and correlated with apparently normoglycemic without features of DM as healthy controls.

\section{Materials and Methods}

The objectives of the present observational hospital-based cross-sectional study were to estimate and correlate serum magnesium with lipid analytes in different clinical groups of both T1DM and T2DM and validate its diagnostic significance. The study was conducted in the department of biochemistry with the collaboration of the medicine department at an Indian government hospital setup. The study comprised a conventional time-bound sample size in 18 months with a total of 250 study subjects. Among these study subjects, there included 200 clinical cases of DM who attended outpatient and inpatient medicine units and 50 normoglycemic healthy controls, by a random sampling technique. The study subjects included both sexes with an age ranged from 10 to 60 years. The study was initiated after an institutional ethical clearance and obtained informed consent from all study participants. Based on inclusion criteria of the study, clinical notes, the clinical state of disease recorded in detailed predesigned patient proforma filled with sociodemographic details, previous medical history of diseases, physical-clinical examinations, duration, treating drug compliances, clinical and relevant diagnostic records with special reference to DM and its complications, subjects were selected randomly and mainly grouped as T1DM or T2DM and further subgrouped in group I, II, and III. Non-diabetes cases with major comorbid conditions like altered renal, respiratory and gastrointestinal functions, chronic diarrhea, on diuretics, chronic alcoholics were excluded from the study. Fifty subjects healthy volunteers normoglycemic with no features of diabetes and no abnormal clinical findings particularly in the context of metabolic and nutritional derangements were randomly selected as healthy controls to compare and correlate the study findings.

\section{Subgroups Clinical States of Study Subjects}

Group I: Newly diagnosed cases of DM not under any treatment. Group II: Stabilized DM under treatment and control.

Group III: Long course, uncontrolled DM associated with noted complications (recorded from case files as hypertension, microvascular complications, retinopathy, peripheral neuropathy, and foot ulcers).

\section{Blood Collection and Biochemical Analysis}

Five milliliters of intravenous blood sample were collected in aseptic precautions after an overnight fast by the use of relevant vacutainers from all study subjects. Blood samples were centrifuged at 3000 r.p.m. for 5 minutes. And plasma and serum were separated for biochemical analysis of study analytes. Separated clear serum samples were labeled and stored in a deep freezer in polythene vials before magnesium analysis was carried on atomic absorption spectrophotometer. The fasting plasma glucose levels were estimated by the glucose oxidase peroxidase method. Serum lipid analytes triacylglycerol (TAG) and total cholesterol were measured by specific kit methods. Statistical comparisons between different groups were done with ANOVA and Pearson's correlation co-efficient. Study data were expressed as a percentage, mean \pm $\mathrm{SD}$. The level of statistical significance was taken as $p \leq 0.05$.

\section{Results and Observations}

The present study randomly included 250 study subjects that comprised 200 DM subjects with 108 males and 92 females. The percentage of male diabetes (54\%) was higher than the percentage of female DM subjects (46\%), which may be due to differences in their lifestyles. Fifty-two (26\%) study subjects were of T1DM and 148 (74\%) subjects were of T2DM, which truly depicted that T2DM was the most commonly suffered type of diabetes. Fifty healthy controls randomly selected included 29 males (58.62\%) and 21 females (41.38\%).

"Table 1 shows the sex-wise distribution of DM and control study subjects". All study subjects included were ranged from 10 to 60 years of age with approximate $12 \%$ of DM subjects between 10 years and 20 years of age, whereas the highest number of 88 (58\%), diabetes patients were of 41 years and 60 years.

"Table 2 shows age and sex-wise distribution of DM study subjects in subgroups". Group I had 50\% of newly diagnosed subjects visited the hospital, with no initiation of treatment. Group II comprised $30 \%$ subjects diagnosed with DM were on follow-up treatment, clinically stabilized or controlled subjects of DM. Group III constituted $20 \%$ of study subjects clinically classified as uncontrolled DM with associated complications. 
Table 1: Sex-wise distribution of diabetes mellitus and control study subjects

\begin{tabular}{|c|c|c|c|}
\hline S. no. & Groups & $\begin{array}{l}\text { Total no. of } \\
\text { subjects }(N=250)\end{array}$ & Percentage \\
\hline \multirow[t]{8}{*}{1} & $\begin{array}{l}\text { Diabetes mellitus sub- } \\
\text { jects }(n=200)\end{array}$ & & \\
\hline & Male & 108 & 54.00 \\
\hline & Female & 92 & 46.00 \\
\hline & Type 1 DM & 52 & 26 \\
\hline & Type 2 DM & 148 & 74 \\
\hline & $\begin{array}{l}\text { Group I (newly diagnosed } \\
\text { diabetes mellitus) }\end{array}$ & 100 & 50 \\
\hline & $\begin{array}{l}\text { Group II (stabilized } \\
\text { diabetes mellitus) }\end{array}$ & 60 & 30 \\
\hline & $\begin{array}{l}\text { Group III (diabetes } \\
\text { mellitus with a long } \\
\text { course, uncontrolled, } \\
\text { with associated } \\
\text { complications) }\end{array}$ & 40 & 20 \\
\hline \multirow[t]{3}{*}{2} & $\begin{array}{l}\text { Controls_apparently } \\
\text { normal non-diabetes } \\
\text { mellitus subjects }(n=50)\end{array}$ & & \\
\hline & Male & 29 & 58.62 \\
\hline & Female & 21 & 41.38 \\
\hline
\end{tabular}

"Table 3 shows the distribution of study subjects of DM as per types and clinical phases". The study found hypomagnesemia associated with hyperglycemic and hyperlipidemic conditions in clinical cases of both T1DM and T2DM. Severe overt hyperglycemia, hypertriacylglycerolemia, hypercholesterolemia, and hypomagnesemia were depicted in group III clinical cases categorized as uncontrolled with clinical complications of DM with the highest statistically significant values of $p<0.001$ when compared with healthy controls. Group I showed a moderate rise in plasma glucose, serum TAG, and cholesterol, and a mild decrease in magnesium with a statistical significance of $p<0.01$. Group II subjects as newly diagnosed cases showed all estimated analytes within reference ranges and showed no statistically significant variations with $p>0.05$ when compared with healthy controls.

"Table 4 shows a comparison of biochemical analytes of study subjects in subgroup I, II, and III vs healthy controls". Statistical insignificance with $p>0.05$ in on comparison of T1DM subjects with T2DM of each I, II, and III subgroup subjects was noted for all studied analytes.

"Table 5 shows a comparison of biochemical analytes in T1DM and T2DM subjects of group I, II, and III". Statistical insignificance with $p>0.05$ was noted for studied subjects of T1DM when compared with T2DM of each I, II, and III subgroup subjects.

"Table 6 shows a correlation of serum magnesium with serum total cholesterol and serum triacylglycerol in group I, II and III subjects of DM". Pearson's correlation coefficient obtained for serum magnesium with serum cholesterol and triacylglycerol in newly diagnosed DM subjects of group I showed a negative correlation coefficient $-0.75, p<0.001$, and -0.1 with $p<0.001$, respectively. Group II controlled DM subjects reported no correlation with $r$ values $0.02 p>0.05$ and uncontrolled DM subjects of group III showed a negative correlation with $-0.156, p<0.01$ and -0.47 , $p<0.01$, respectively. Thus, these study results suggested biochemical varied hypomagnesemia was inversely correlated with dyslipidemias and overt hyperglycemia in T1DM and T2DM of studied subjects.

\section{Discussion}

Present observational hospital-based cross-sectional study design, conducted to evaluate serum magnesium with lipid analytes in different clinical groups of DM of type 1 and type 2, showed biochemical variations of hypomagnesemia, inversely correlated with hyperglycemia, hypertriacylglycerolemia, hypercholesterolemia when compared and correlated with normoglycemic healthy controls. Statistically significant inverse correlations of studied analytes observed with $(p<0.001)$ in group III subjects associated with symptomatic complications, $(p<0.01)$ in group I newly diagnosed non-treated diabetes subjects, and non-significant $(p>0.05)$ in group II clinically stabilized study subjects. However, the study results noted statistical insignificant values for study analytes with $p>0.05$ when compared for studied subjects of T1DM with T2DM for each subgroup A, B, and C. Thus, the present study identified hypomagnesemia in severe hyperglycemichyperlipidemic with similar approaches for all biochemical varied and correlated analytes in both T1DM and T2DM subjects in studied clinical cases. The study results of hypomagnesemia may be linked to the kidney's osmotic diuresis ability to excrete magnesium during a phase of severe hyperglycemia. Hypermagnesemia depicted paralleled hypomagnesemia in young diabetic subjects in Bangladesh. ${ }^{20}$ Osmotic diuresis due to overt hyperglycemia excreted out urine magnesium which lowered blood levels of magnesium to cause chronic complications of diabetes, further magnesium supplementation in these patients has been suggested to improve proven hypomagnesemia and its complications. ${ }^{21}$ Present study results were concordant to previous research studies that showed hypomagnesemia frequently present in cases of DM with an inadequate metabolic control in DM. Hypomagnesemia may be directly related to micro- and macrovascular complications that lead to cardiovascular disease, retinopathy, and neuropathy. ${ }^{22}$ Hypomagnesemia noted in 65\% Ethiopians with $\mathrm{DM}^{23}$ reported poor glycemic control in hypomagnesemia patients when compared with normomagnesemia patients, and magnesium levels had shown a positive correlation with the severity of diabetes. ${ }^{24,25}$

Hussain KSA in their case-control study of serum lipid profile and serum magnesium levels in newly diagnosed type 2 diabetes subjects and normal individuals depicted similar results as reported in the present study with low serum magnesium and high TAG and total cholesterol mean levels significantly $(p<0.001)$ in diabetics compared with the controls. ${ }^{26}$ Poor glycemic regulation affects serum $\mathrm{Mg}$ levels in DM, which affects both glycemic regulation and the occurrence of complications. ${ }^{27}$ Egyptian children study with type 1 diabetes evidenced out hypomagnesemia with poor diabetes control and higher atherogenic lipid parameters and suggested low serum magnesium may be a factor in the pathogenesis of poor glycemic control and abnormal lipid profile. ${ }^{28}$ Correction of hypomagnesemia in type 1 diabetes children with oral Mg supplements was associated with optimization of glycemic control and reduction of atherogenic lipid fraction with an increase in protective lipid fraction. ${ }^{26}$ Ramadass with his co-workers pointed out that hypomagnesemia was linked to poor control of DM type 2 and depletion of serum magnesium occurred exponentially with duration of disease. Degree of control of diabetes and magnesium status, studied by Khubchandani and Sanghani reported hypomagnesemia and increased serum 
Biochemical Variations of Serum Magnesium with Lipid Analytes in Different Clinical Groups of T1DM and T2DM

Table 2: Age and Sex-wise distribution of diabetes mellitus study subjects

\begin{tabular}{llllll}
\hline S. no. & Age group in years & Number of males $(N=108)$ & Number of females $(N=92)$ & Total 200 & Percentage \\
\hline 1 & $10-20$ & 13 & 11 & 24 & 12.00 \\
2 & $21-40$ & 32 & 28 & 60 & 30.00 \\
3 & $41-60$ & 63 & 53 & 116 & 58.00 \\
\hline
\end{tabular}

Table 3: Distribution of diabetes mellitus study subjects as per types and conditions

\begin{tabular}{llllll}
\hline S. no. & Group of DM & Number of T1DM & Number of T2DM & Total DM subjects & Percentage \\
\hline 1 & Group I newly diagnosed DM & 26 & 74 & 100 & 50.00 \\
2 & Group II controlled DM & 16 & 44 & 60 & 30.00 \\
3 & Group III uncontrolled DM with & 10 & 30 & 40 & 20.00 \\
& associated complications & 52 & 148 & 200 & 100 \\
\hline
\end{tabular}

Table 4: Comparison of biochemical analytes of study subjects in subgroup I, II, and III v/s healthy controls

\begin{tabular}{|c|c|c|c|c|c|c|c|c|}
\hline S. no. & $\begin{array}{l}\text { Biochemical param- } \\
\text { eters }\end{array}$ & $\begin{array}{l}\text { Healthy controls } \\
(N=50) \text { Mean } \\
\pm \text { S.D. }\end{array}$ & $\begin{array}{l}\text { Group / subjects } \\
(N=100) \\
\text { Mean } \pm \text { S.D. }\end{array}$ & "p"value & $\begin{array}{l}\text { Group /l subjects } \\
(N=60) \text { Mean } \\
\pm \text { S.D. }\end{array}$ & "p"value & $\begin{array}{l}\text { Group III subjects } \\
(N=40) \text { Mean } \\
\pm S . D .\end{array}$ & " $p$ " value \\
\hline 1 & $\begin{array}{l}\text { Fasting plasma glu- } \\
\text { cose }(\mathrm{mg} / \mathrm{dL})\end{array}$ & $92.25 \pm 4.39$ & $186.16 \pm 17.72$ & $<0.01$ & $100.75 \pm 6.10$ & $>0.05$ & $262.00 \pm 23.49$ & $<0.001$ \\
\hline 2 & $\begin{array}{l}\text { Serum magnesium } \\
(\mathrm{mmol} / \mathrm{L})\end{array}$ & $2.002 \pm 0.03$ & $1.562 \pm 0.03$ & $<0.01$ & $1.976 \pm 0.04$ & $>0.05$ & $1.396 \pm 0.025$ & $<0.001$ \\
\hline 3 & $\begin{array}{l}\text { Serum total choles- } \\
\text { terol }(\mathrm{mg} / \mathrm{dL})\end{array}$ & $179.0 \pm 19.69$ & $248.32 \pm 16.66$ & $<0.01$ & $183.73 \pm 31.27$ & $>0.05$ & $292.2 \pm 12.04$ & $<0.001$ \\
\hline 4 & $\begin{array}{l}\text { Serum triacylglycerol } \\
(\mathrm{mg} / \mathrm{dL})\end{array}$ & $81.6 \pm 21.47$ & $132.9 \pm 9.48$ & $<0.01$ & $94.2 \pm 18.40$ & $>0.05$ & $210.7 \pm 31.72$ & $<0.001$ \\
\hline
\end{tabular}

cholesterol and triglyceride levels were responsible for micro- and macrovascular complications in diabetes. ${ }^{29,30}$ Manonmani and Manimekalai in their study with the south Indian population also reported hypomagnesemia in type $2 \mathrm{DM}$ and an inverse correlation with the duration of diabetes. ${ }^{31}$ Old age, poor glycemic control, and low eGFRcr were significant predictors of low serum magnesium in Nepalese patients of DM. ${ }^{32}$ Biochemical indicators of low magnesium, high TAG in association with enhanced $\mathrm{HbA}$ 1c percent could serve as a reliable for insulin sensitivity, and resistance of insulin status and action. ${ }^{33}$ Sendhav et al. also depicted a significant inverse correlation with hypomagnesemia and dyslipidemia with raised fasting plasma glucose in DM patients when compared to healthy controls. ${ }^{34}$ Dineshbabu and Tonk in their recent study concluded hypomagnesemia in T2DM was correlated with various complications and stated magnesium can be considered as a nutritional supplement in patients with diabetes to reduce the incidence of vascular complications. ${ }^{35}$ Subjects with type 2 diabetes showed a strong relationship with foot ulcers with depleted serum magnesium. ${ }^{36}$ Duration of diabetic foot ulcers (grade I and II) increased with duration of diabetes increase and serum magnesium decrease. ${ }^{25}$ Both extracellular and intracellular chronic latent magnesium deficiency in overt clinical hypomagnesemia was frequently associated with T2DM especially in those with poorly controlled glycemic profiles. ${ }^{9}$ A recently published systematic review and meta-analysis by Rodrigues et al. fairly depicted an association between reduced levels of magnesium and poor glycemic control in patients with T1DM. ${ }^{37}$ Previous studies depicted further depletion of magnesium decreased atherogenic lipid fractions and reduced insulin-stimulated glucose uptake, considered as a hidden link between the pathogenesis of diabetes and its complications. Early recognition of dysregulated magnesium metabolism with correction of an electrolyte imbalance could be crucial in the prevention of diabetic complications. Glucokinase, potassium-ATP channels, L-type $\mathrm{Ca}^{2+}$ channels in pancreatic $\beta$-cells for preceding insulin secretion are regulated by intracellular $\mathrm{Mg}^{2+}$, moreover, intracellular $\mathrm{Mg}^{2+}$ concentrations make $\mathrm{Mg}^{2+}$ a direct factor in the development of insulin resistance linked with insulin receptor autophosphorylation. ${ }^{38}$ A study showed decreased serum total cholesterol, serum low-density lipoprotein (LDL)cholesterol, and apolipoprotein B through acute and chronic Mg supplementation. Oral $\mathrm{MgO}$ supplementation decreased insulinstimulated glucose uptake by $35 \%$ after 24 weeks, food ingestion is rich in magnesium corrected low levels of magnesium with reduction of DM complications. ${ }^{39-41}$ Uncertainty was associated in the measurement of serum total magnesium concentration and depiction of extracellular Mg deficiency in patients with arrhythmia and DM, Mg deficiency in patients with essential hypertension was not supported by intracellular accumulation of $\mathrm{Mg} .{ }^{42,43}$ Song with his co-workers reported oral magnesium supplementation for 4-16 weeks effectively reduced fasting plasma glucose and raised HDL cholesterol in patients with type 2 diabetes, however, longterm benefits and safety of magnesium treatment on glycemic control could not be determined. ${ }^{44}$ The limitation of the present study is an estimation of total extracellular magnesium alone without knowledge of intracellular and extracellular free ionized physiological magnesium levels, to get a holistic magnesium metabolic approach, which had the challenge to correlate its deficiency as a bidirectional association between dyslipidemia in 
Table 6: Correlation of serum magnesium with serum total cholesterol and serum triacylglycerol in group I, II, and III subjects of diabetes mellitus

\begin{tabular}{llll}
\hline $\begin{array}{l}\text { Biochemical } \\
\text { parameters }\end{array}$ & Group I & Group II & Group III \\
\hline Correlation & $n=100$ & $n=60$ & $n=40$ \\
\hline & $\begin{array}{l}\text { Correlation } \\
\text { coefficient }\end{array}$ & $\begin{array}{l}\text { Correlation } \\
\text { coefficient }\end{array}$ & $\begin{array}{l}\text { Correlation } \\
\text { coefficient }\end{array}$ \\
\hline $\begin{array}{l}\text { Serum magnesium } \\
\text { with }\end{array}$ & -0.75 & 0.02 & -0.156 \\
$\begin{array}{l}\text { Serum total } \\
\text { cholesterol }\end{array}$ & $p<0.001$ & $p>0.05$ & $p<0.01$ \\
$\begin{array}{l}\text { Serum magnesium } \\
\text { with serum } \\
\text { triacylglycerol }\end{array}$ & -0.1 & 0.01 & -0.47 \\
\hline & $p<0.001$ & $p>0.05$ & $p<0.01$ \\
\hline
\end{tabular}

clinical conditions and complications of T1DM and T2DM. Based on biochemical varied study data, compared and correlated in conjunction with previous research studies, estimation of serum magnesium along with lipid profile to be included as an initial diagnostic protocol for both T1DM and T2DM and advice for dietary supplementation of magnesium may prevent its deficiency and have a reductionist approach toward its complications as an antidiabetic treatment protocol.

\section{Conclusion}

The present study depicted biochemical variations of hypomagnesemia in an overt hyperglycemic-hyperlipidemic studied clinical groups of both T1DM and T2DM. In conjunction with reviewed research findings, it is suggested to prescribe estimation of serum magnesium as a routine or extended diagnostic profile investigation in known clinical cases of both T1DM and T2DM for early screening, periodic monitoring for its deficiency, and better management of clinical cases through its supplementation to prevent the development of long-standing critical diabetes complications. Prospects might remain to conduct populationbased prospective cohort studies for clarification of facts and obtain a holistic approach with both extracellular, intracellular, total, and ionized magnesium concentrations in different types, clinical states, and complications of DM.

\section{References}

1. American Diabetes Association. 2. Classification and diagnosis of diabetes. Dia Care 2017;40(Suppl. 1):S11-S24. DOI: 10.2337/dc17-S005.

2. WHO [Internet]. Available from: https://www.who.int/health-topics/ diabetes\#tab=tab_1.

3. Kaveeshwar SA, Cornwall J. The current state of diabetes mellitus in India. Australas Med J 2014;7(1):45-48. DOI: 10.4066/AMJ.2014.1979.

4. Tabish SA. Is diabetes becoming the biggest epidemic of the twentyfirst century? Int J Health Sci (Qassim) 2007;1(2):V-VIII.

5. Shahid SM, Rafique R, Mahboob T. Electrolytes and sodium transport mechanism in diabetes mellitus. Pak J Pharm Sci 2005;18(2):6-10.

6. Marschner H. Mineral nutrition of higher plants. 2nd ed., [5. print.], San Diego: Academic Press; 2002. p. 889.

7. Zhang Y, Li Q, Xin Y, et al. Association between serum magnesium and common complications of diabetes mellitus. Gómez C, Schwarzacher SP, Zhou H, ed. THC 2018;26:379-387. DOI: 10.3233/THC-174702.

8. Rodríguez-Morán M, Simental Mendía LE, Zambrano Galván G, et al. The role of magnesium in type 2 diabetes: a brief based-clinical review. Magnes Res 2011;24(4):156-162. DOI: 10.1684/mrh.2011.0299. 
9. Barbagallo M. Magnesium and type 2 diabetes. WJD 2015;6(10):1152. DOI: 10.4239/wjd.v6.i10.1152.

10. Erasmus RT, Olukoga AO, Alanamu RA, et al. Plasma magnesium and retinopathy in black African diabetics. Trop Geogr Med 1989;41(3):234-237.

11. Kao WHL, Folsom AR, Nieto FJ, et al. Serum and dietary magnesium and the risk for type 2 diabetes mellitus: the atherosclerosis risk in communities study. Arch Intern Med 1999;159(18):2151. DOI: 10.1001/ archinte.159.18.2151.

12. Djurhuus MS, Skøtt P, Hother-Nielsen O, et al. Insulin increases renal magnesium excretion: a possible cause of magnesium depletion in hyperinsulinaemic states. Diabet Med 1995;12(8):664-669. DOI: 10.1111/j.1464-5491.1995.tb00566.x.

13. Nasri H. Consequences of hypomagnesemia in type 2 diabetes mellitus patients. consequences of hypomagnesemia in type 2 diabetes mellitus patients [Internet]. J Renal Inj Prev 2014;3(4):99-100. DOI: 10.12861/jrip.2014.28.

14. Grafton G, Bunce CM, Sheppard MC, et al. Effect of $\mathrm{Mg}^{2+}$ on $\mathrm{Na}^{+}$ -dependent inositol transport: role for $\mathrm{Mg}^{2+}$ in etiology of diabetic complications. Diabetes 1992;41(1):35-39. DOI: 10.2337/diab.41.1.35.

15. de Valk HW, Hardus PL, van Rijn HJ, et al. Plasma magnesium concentration and progression of retinopathy. Diabetes Care 1999;22(5):864-865. DOI: 10.2337/diacare.22.5.864.

16. Gröber U, Schmidt J, Kisters K. Magnesium in prevention and therapy. Nutrients 2015;7(9):8199-8226. DOI: 10.3390/nu7095388.

17. Velayutharaj A, Saraswathi R, Shivakumar R, et al. Association of serum magnesium with glycemic control and insulin resistance in patients with type 2 diabetes mellitus. Int J Curr Res Rev 2016;8(13):17.

18. Sajjan N, Shamsuddin M. A study of serum magnesium and dyslipidemia in type 2 diabetes mellitus patients. Inter J Clin Bio Res 2016;3(1):36. DOI: 10.5958/2394-6377.2016.00007.1.

19. Yu L, Zhang J, Wang L, et al. Association between serum magnesium and blood lipids: influence of type 2 diabetes and central obesity. $\mathrm{Br}$ J Nutr 2018;120(3):250-258. DOI: 10.1017/S0007114518000685.

20. Khan $L A$, Alam $A M$, Ali $L$, et al. Serum and urinary magnesium in young diabetic subjects in Bangladesh. Am J Clin Nutr 1999;69(1):70-73. DOI: 10.1093/ajcn/69.1.70.

21. Sales $\mathrm{CH}$, Pedrosa L, de FC. Magnesium and diabetes mellitus: their relation. Clin Nutr 2006;25(4):554-562. DOI: 10.1016/j. clnu.2006.03.003.

22. Tosiello L. Hypomagnesemia and diabetes mellitus. A review of clinical implications. Arch Intern Med 1996;156(11):1143-1148. DOI: 10.1001/archinte.1996.00440100029005.

23. Seyoum B, Siraj ES, Saenz C, et al. Hypomagnesemia in ethiopians with diabetes mellitus. Ethn Dis 2008;18(2):147-151.

24. Gupta NK, Sharma S, Kaushik G, et al., Association Between Indexes of Insulin Sensitivity/Resistance and Serum Magnesium Levels in Overweight Diabetic Subjects. :6.

25. Jamali AA, Jamali GM, Jamali NH, et al. Assessment of serum magnesium level in type 2 diabetes mellitus with diabetic foot ulcers (grade I and II) at Nawabshah, Pakistan. IJCM 2018;09(02):104-116. DOI: 10.4236/ijcm.2018.92011.

26. Shahbah D, Hassan T, Morsy S, et al. Oral magnesium supplementation improves glycemic control and lipid profile in children with type 1 diabetes and hypomagnesaemia. Medicine 2017;96(11):e6352. DOI: 10.1097/MD.0000000000006352.

27. Arpaci $D$, Tocoglu AG, Ergenc $H$, et al. Associations of serum magnesium levels with diabetes and diabetic complications. EJEA [Internet] 2015. DOI: 10.1530/endoabs.37.EP490Available from: http:// www.endocrine-abstracts.org/ea/0037/ea0037EP490.htm.

28. Shahbah D, El Naga AA, Hassan T, et al. Status of serum magnesium in Egyptian children with type 1 diabetes and its correlation to glycemic control and lipid profile. Medicine 2016;95(47):e5166. DOI: 10.1097/ MD.0000000000005166.

29. Khubchandani AS, Sanghani H, Study of Serum Magnesium and HbA1C in Diabetic Patients along with Changes in their Lipid Profiles. :3.

30. Ramadass S, Basu S, Srinivasan AR. SERUM magnesium levels as an indicator of status of diabetes mellitus type 2. Diabetes Metab Syndr 2015;9(1):42-45. DOI: 10.1016/j.dsx.2014.04.024.

31. Manonmani M, Manimekalai K. A study of serum magnesium level in type 2 diabetes mellitus patients. JDM 2018;08(02):20-26. DOI: 10.4236/jdm.2018.82003.

32. Pokharel DR, Khadka D, Sigdel M, et al. Association of serum magnesium level with poor glycemic control and renal functions in Nepalese patients with type 2 diabetes mellitus. Diabetes Metabol Syndr 2017;11:S417-S423. DOI: 10.1016/j.dsx.2017.03.028.

33. Srinivasan AR, Niranjan G, Kuzhandai Velu V, et al. Status of serum magnesium in type 2 diabetes mellitus with particular reference to serum triacylglycerol levels. Diabetes Metabol Syndr 2012;6(4):187189. DOI: $10.1016 /$ j.dsx.2012.09.001.

34. Sendhav SS, Kakaiya A, Chatterjee B. Evaluation of serum magnesium level along with lipid profile in a Gujarati population diagnosed with diabetes mellitus. Indian J Med Biochem 2017;21(2):112-116. DOI: 10.5005/jp-journals-10054-0032.

35. Dineshbabu S, Tonk RS. Study of relation between serum magnesium levels and vascular complications in patients of type 2 diabetes mellitus. IJMSCI 2019;6(09):4574-4591. DOI: 10.18535/ijmsci/ v6i9.03.

36. Rodriguez-Moran M, Guerrero-Romero F. Oral magnesium supplementation improves insulin sensitivity and metabolic control in type 2 diabetic subjects: a randomized double-blind controlled trial. Diabetes Care 2003;26(4):1147-1152. DOI: 10.2337/ diacare.26.4.1147.

37. Rodrigues AK, Melo AE, Domingueti CP. Association between reduced serum levels of magnesium and the presence of poor glycemic control and complications in type 1 diabetes mellitus: a systematic review and meta-analysis. Diabetes Metabol Syndr 2020;14(2):127134. DOI: 10.1016/j.dsx.2020.01.015.

38. Gommers LMM, Hoenderop JGJ, Bindels RJM, et al. Hypomagnesemia in type 2 diabetes: a vicious circle? Diabetes 2016;65(1):3-13. DOI: 10.2337/db15-1028.

39. Djurhuus MS, Henriksen JE, Klitgaard NA, et al. Effect of moderate improvement in metabolic control on magnesium and lipid concentrations in patients with type 1 diabetes. Diabetes Care 1999;22(4):546-554. DOI: 10.2337/diacare.22.4.546.

40. Rodríguez M, Guerrero-Romero F. Low serum magnesium levels and foot ulcers in subjects with type 2 diabetes. Arch Med Res 2001;32(4):300-303. DOI: 10.1016/S0188-4409(01)00298-3.

41. Lal J, Vasudev K, Kela AK, et al. Effect of oral magnesium supplementation on the lipid profile and blood glucose of patients with type 2 diabetes mellitus. J Assoc Physicians India 2003;51: 37-42.

42. Sasaki $\mathrm{S}$, Oshima $\mathrm{T}$, Matsuura $\mathrm{H}$, et al. Abnormal magnesium status in patients with cardiovascular diseases. Clin Sci 2000;98(2):175-181. DOI: $10.1042 / \mathrm{cs} 0980175$.

43. Ma J, Folsom AR, Melnick SL, et al. Associations of serum and dietary magnesium with cardiovascular disease, hypertension, diabetes, insulin, and carotid arterial wall thickness: the ARIC study. J Clin Epidemiol 1995;48(7):927-940.

44. Song $Y, H e K$, Levitan EB, et al. Effects of oral magnesium supplementation on glycaemic control in type 2 diabetes: a metaanalysis of randomized double-blind controlled trials. Diabet Med 2006;23(10):1050-1056. 